\title{
Chemical Constituents of Essential Oil from Anethum sowa L. Herb (Leaf and Stem) Growing in Bangladesh
}

\author{
M. Moshfekus Saleh-e-In a, Abida Sultana ${ }^{a}$, Mozaffar Husain ${ }^{b}$ and Sudhangshu Kumar Roy ${ }^{\text {* }}$ \\ ${ }^{a}$ Department of Chemistry, Government Bangla College of National University, Gazipur and \\ *bCSIR Laboratories, Dhaka-1205, Bangladesh
}

\begin{abstract}
The oil obtained by the hydro-distillation method from the fresh leaves and stems of Anethum sowa L. (Dill) herb was analyzed by GC-MS. Twenty compounds were isolated and identified. The major constituents were apiole (25.39\%), o-cymene (15.25\%), $\alpha$-thujene (14.84\%), $\beta$ phellandrene (7.17\%), 6,6-dimethyl-2-(3-oxobutyl) bicyclo(3.1.1) heptan-3-one (6.90\%), exo-2-hydroxycineol (5.03\%), limonene (4.13\%), 3-isopropyl-4-methyl-1-pentyn-3-ol (2.89\%), myristicine (2.46\%) and dihydroumbellulone (2.14\%).
\end{abstract}

Key words : Anethum sowa L. Essential oil, GC-MS, Apiole

\section{Introduction}

Anethum sowa L. (Internationally Dill, Bengali Shulfa) belongs to the family Apiaceae (Umbelliferae) has a very long history of herbal use going back more than 2000 years. It is an annual, glabrous aromatic cold weather condiment crop in northern plains of India and Bangladesh (Husain et al., 1988). It is also grown widely in other countries of South East Asia and Japan for its fresh aromatic leaves and fruit (Anonymous, 1985). Anethum sowa L. has also been sometimes referred to as a variety of Anethum graveolens L. the European Dill, whose cultivation is preferred in Europe and USA. Its fruits are longer but less fragrant than Anethum graveolens L. (Umbelliferae). The Dill herb grows up to 76 $\mathrm{cm}$. in height, which has small feathery leaves and stands on sheathing foot-stalks with linear and pointed leaflets. Stem is erect, branched, cylindrical, striated, smooth and pale green (Anonymous, 1985 ; Chopra, 1982 ; Husain et al., 1988).

Both seed and freshly cut entire herb including stem, leaf and fruit are widely used for flavoring of food, beverages, fragrance in cosmetics and in various medicinal preparations. The oil and its emulsion in water are used in gastrointestinal disorders and an important ingredient of gripe water (Anonymous, 1985; Chopra, 1982). Biological and pharmacological studies of this plant revealed antimicrobial, antioxidative and antispasmodic activities (Baslas, 1971; Woolf, 1999; Maruzzella, 1960).
Essential oils of Dill herb and seed have been reported by many researchers (Guenther, 1953; Koedam et al., 1979; Lawrence, 1980; Schreier et al., 1981; Husain et al., 1994; Denys et al., 1995; Ahmed, 1990; Huopalahti, 1984. Halva, 1988; Virmane and Data 1970). The purpose of this study was to determine the chemical constituents of Dill herb essential oil, the content of aroma causing compounds as well as to determine the feasibility of large scale herb production in Bangladesh. The literature search shows that, there is no previous report on the chemical composition of the essential oil of Dill herb grown in Bangladesh.

\section{Materials and Methods}

The fresh Dill herb was collected from the district of Sirajgonj in Bangladesh in December 2002. The plant was identified by Bangladesh National Herbarium Centre, Dhaka. A voucher specimen (DACB Accession Number31,282 ) of the plant was deposited in the Herbarium.

The essential oils of leaves and stems were obtained by hydro-distillation method from finely chopped fresh herb after separation of its root in a Clevenger type apparatus for 2 hours. The oil was collected, dried over anhydrous sodium sulphate and refrigerated at $4^{\circ} \mathrm{C}$. The yield of the oil was $0.30 \%$ (w/w) on fresh weight basis.

\footnotetext{
* Corresponding author: E-mail: : saleheen_sosthe@yahoo.com
} 


\section{GC/MS Analysis}

The analysis of the oils was carried out by GC-MS electron impact ionization method on GC-17A gas chromatograph (Shimadzu) with FID detector coupled to a GC-MS QP5050A mass spectrometer (Shimadzu): fused silica capillary column (30 m x $0.25 \mathrm{~mm}, 0.25 \mathrm{~mm}$ film thickness) coated with DB-1 (J\&W). Column temperature $40^{\circ} \mathrm{C}$ (2 min.) was raised to $250^{\circ} \mathrm{C}$ at the rate of $5^{\circ} \mathrm{C} / \mathrm{min}$. Injection port temperature was $250^{\circ} \mathrm{C}$ and injection volume $0.1 \mu \mathrm{L}$. Helium gas was used as carrier gas at constant pressure of $100 \mathrm{Kpa}$, flow rate $20 \mathrm{ml} / \mathrm{min}$. Acquisition parameters full scan : scan range 40-450 amu. Identification of the compounds were confirmed by computer matching of their mass spectral fragmentation pattern with those of compounds in NIST (National Institute for Standard and Technologies) 107 built in Lis Libraries Shimadzu Corporation, Japan. Sample was dissolved in chloroform. Mass spectra were recorded at 70 $\mathrm{eV}$. The GC/MS data of the oil are shown in Table I.

\section{Results and Discussion}

In the study Dill yielded 0.3\% (w/w) light yellow colored oil with a typical herb odor on fresh weight basis. It is reported in the literature that the oil percentages ranges from $0.1 \%$ to $0.46 \%$ on fresh weight basis (Denys et al., 1995; ElGengaihi et al., 1978; Zlatev et al., 1974).

Twenty constituents have been identified in the oil by GC and GC/MS (Table I). The constituents are listed in the order of their peak. The oil is characterized by fairly high concentration of monoterpenes (56.87\%) comprising of monoterpene hydrocarbons (44.01\%) and oxygenated monoterpenes $(12.86 \%)$. Only one sesquiterpene a-selinene $(1.08 \%)$ consisted of the sesquiterpene hydrocarbon, a diterpene compound phytol (1.67\%) consisted of the oxygenated diterpene, phenylpropanoid constituents apiole (25.39\%) and myristicine $(2.46 \%)$ were identified in the oil. Undecane $(1.22 \%)$ and 3-isopropyl-4-methyl-1-pentyn-3-ol (2.89\%) were also found in the investigation as alkane and alcohol type compounds respectively.

Other components were present in an amount of $8.42 \%$. Beside these, the predominant components were: o-cymene (15.25\%), a-thujene (14.84\%), b-phellandrene (7.17\%), 6,6dimethyl-2-(3-oxobutyl)bicycle (3.1.1) heptan-3-one (6.90\%), exo-2-hydroxycineole (5.03\%), limonene (4.13\%), and dihydroumbellulone (2.14\%). Apiole an undesirable toxic constituent was found in the highest amount of the oil. This ingredient brings down its quality. This constituent could be separated or removed from the oil by fractional distillation (Shankaracharya et al., 2000). Though it is toxic in nature it can be used as synergist with insecticides. It has also shown a stronger oviposition deterrent against Callosobruchus maculates than d-carvone (Lichtenstein et al., 1974 ; Tomar et al., 1979; Tripathi et al., 2001).

The literature survey revealed that the compounds like $\alpha$-thujene (0.19-0.41\%), $\alpha$-pinene (0.98-2.16\%), $\beta$-phellandrene (11.87-19.08\%), dill ether (16.62-30.18\%) and myristicine (0.01-0.19\%) were found in the herb oil (Denys et al., 1995). In another publication (Halva et al., 1988) the

Table I. Chemical composition of the Dill herb (leaf and stem) essential oil

\begin{tabular}{|c|c|}
\hline Compounds & Relative\% \\
\hline$\alpha$ - pinene $^{\mathrm{c}}$ & 1.09 \\
\hline$\alpha$ - thujene ${ }^{\mathrm{c}}$ & 14.84 \\
\hline o-cymene ${ }^{c}$ & 15.25 \\
\hline$ß$-phellandrene ${ }^{\mathrm{c}}$ & 7.17 \\
\hline Limonene $^{\mathrm{c}}$ & 4.13 \\
\hline Terpinolene $\mathrm{c}^{\mathrm{C}}$ & 1.53 \\
\hline Undecane $^{\mathrm{f}}$ & 1.22 \\
\hline Dill ether ${ }^{\mathrm{b}}$ & 1.48 \\
\hline 1,3-cyclohexadiene,2-methyl-5- & \\
\hline (1-ethylethyl)-, monoepoxide ${ }^{\mathrm{b}}$ & 1.75 \\
\hline 6,6-dimethyl-2-(3-oxobutyl) bicyclo & \\
\hline (3.1.1) heptan-3-one. & 6.90 \\
\hline Camphenol- $6^{\mathrm{b}}$ & 1.34 \\
\hline Lilac alcohol B ${ }^{\text {b }}$ & 1.12 \\
\hline exo-2-hydroxycineole ${ }^{\mathrm{b}}$ & 5.03 \\
\hline 3-isopropyl -4-methyl-1-pentyn-3-ol ${ }^{\mathrm{g}}$ & 2.89 \\
\hline Dihydroumbellulone ${ }^{\mathrm{b}}$ & 2.14 \\
\hline Cyclohexanone,2-isopropyl-2,5-dimethyl & 1.52 \\
\hline Myristicin $^{\mathrm{a}}$ & 2.46 \\
\hline Apiol $^{\mathrm{a}}$ & 25.39 \\
\hline$\alpha$-selinene ${ }^{\mathrm{d}}$ & 1.08 \\
\hline Phytol $^{\mathrm{e}}$ & 1.67 \\
\hline
\end{tabular}

Notes: Compounds arranged in the order of the peak numbers. Superscripts a, b, c, d, e, f \& g indicates for phenylpropanoid, oxygenated monoterpenes, monoterpene hydrocarbons, sesquiterpene, diterpene, alkane, alcohol constituents respectively.

compounds $\alpha$-pinene (1.2-1.4), $\beta$-phellandrene (6.4-8.5\%), dill ether (21.6-37.7\%), limonene (2.1-2.8\%) and myristicine $(0.3-2.1 \%)$ were reported. In the present study almost the similar compounds as the earlier reports (Denys et al., 
1995; Halva et al., 1988) were found. In addition to that, another 5 compounds like (1) phytol, (2) $\alpha$-selenene, (3) 6,6-Dimethyl-2-(3-oxobutyl) bicycle (3.1.1)heptan-3-one, (4) 3-Isopropyl-4-methyl-1-pentyn-3-ol and (5) cyclohexanone, 2-isopropyl-2,5-dimethyl were also found. It appears that these five compounds were first identified in this study.

\section{Conclusion}

The results of this study are of interest in respect to the processing of dill herb. The distillation and the drying process are to be performed in such a way that minimum loss of volatile components occurs. These essential oils have the potential to be used in food as flavoring and natural preservatives, pharmaceuticals, cosmetics and may also be considered as active ingredients in medical preparations.

\section{Acknowledgement}

Authors are thankful to the Director, BCSIR Laboratories, Dhaka. Bangladesh for giving the permission to conduct the research work. The authors offer their thanks to Md. Zamilur Rahman, S.O., and Md. Mosharraf Hossain, Jr. Tech., BCSIR Labs., Dhaka and Saimuzzaman (Babu) of Roads Res. Lab. Mirpur, Dhaka, for the assistance during the investigation. Authors are grateful to Bangladesh National Herbarium Centre Scientist Mr. Samsul Hoque for identifying the plant.

\section{References}

Ahmed A., Misra L. N. and Nigam M. C. (1990) A dihydrobenzofuran from India dill seed oil. J. Phytochemistry. 29(6): 2035-2037.

Anonymous. (1985) The Wealth of India. Raw Materials. Council of Scientific and Industrial Research, New Delhi, India, Vol. I-A, p-272-275.

Baslas B. K. and Baslas R. K. (1971) Chemical studies into the essential oils form the plants of Anethum graveolens \& Anetham sowa (dill oils), Indian Perfumer. 15: 27-29.

Chopra R.N., Chopra I.C., Honda K.L. and Kapur L.D. (1982) Chopra's Indigenous Drugs of India. Academic Publishers, New Delhi, India 2nd Ed. pp. 692-93.

Denys J. C., James E. S. and Markp W. (1995) Characterization of essential oil of dill (Anethum graveolens L). J Essent Oil Res . 7: 11-20.
El-Gengaihi S. E. and Hornok L. (1978) The effect of plant age on content and composition of dill essential oil Anethum graveolens L. Acta Horticult. 73: 213-218.

Guenther E. (1953) The Essential Oils, Vol-IV, 1st Edn., D. Van Nostrand Co. Inc. New York, p. 633.

Halva S., Huopalahti R. and Franzch M. (1988) Herb yield and essential oil of dill (Anethum graveolens L) at different locations. J. Agric Sci, Finland. 60: 93-100.

Huopalahti R. (1984) Effect of latitude on the composition and content of aroma compounds In dill, (Anethum graveolens L.) Lebensm.-Wiss.u.-Technol. 17: 16-19.

Husain A., Virmani O. P., Sharma A. and Misra L. N. (1988) Major essential oil-bearing plants of India. CIMAP, Lucknow, pp. 87-95.

Husain H. (1994) Status report on aromatic and essential oilbearing plants in NAM countries publication and information directorate (CSIR). 1: 71-72.

Koedam A., Schaffer J. J.and Bear H. S. A. (1979) Comparison of isolation of procedures for essential oils, II Ajowan, Caraway,Coriander and Cumin, 2. Lebensm, J. Undes, Vigorously. 68: 106-111.

Lawrence B. (1980) New trends in essential oils. Perfume Flavour. 5: 6-16.

Lichtenstein E. P., Tony T. L., Schulz K. R., Schnoes H. K., and Carter G. T. (1974) Insecticidal and synergistic components isolated from dill plants. J. Agr. Food Chem. 22(4): 658.

Maruzzella J. C., Scrandis J. B., Scrandis and Grabon G. (1960) Action of odoriferous organic chemicals and essential oils on wood-destroying fungi. Plant Dis. Rep. 44: 789-792.

Schreier P., Drawert F. and Heindze I. (1981) The quantitative composition of natural and technologically changed aromas of plants. VIII. Volatile constituents of fresh dill herb. Lebensm.Wiss.Technol. 14: 150-152.

Shankaracharya N. B., Mohon R. L. J., Puranaik J. and Nagalakshmi S. (2000) Studies on chemical and technological aspects of Indian dill seed (Anethum sowa, Roxb), J. Food. Sec. Technol. 37(4): 368 -372. 
Tomar S. S., Maheshwari M. L. and Mukerjee S. K. (1979) Synthesis and synergistic activity of dillapiole based pyrethrum synergists. J Agric Food Chem. 27(3): 547.

Tripathi A. K., Prajapati V., Aggarwal K. K. and Kumar S. (2001) Insecticidal and ovicidal activity of the essential oil of Anethum sowa kurz against Callosobruchus maculatus F.(Coleoptera ; Bruchidae) Insect Sci Appllic. 21(1): 61-66.
Virmani O. P. and Datta S. C. (1970) Essential oil of Anethum graveolens. Flavour Ind. 1: 856-862.

Woolf A. (1999) Essential oil poisoning, Journal of Clinical Toxicology. 37: 721-727.

Zlatev S. and Balinova A. T. (1974) Dynamics of essential oil accumulation in dill (Anethum graveolens). Rastenievud Nauki. 11(3): 69-76.

Received : November 03, 2008;

Accepted : September 09, 2009 